\title{
Significados do Consumo de Tatuagem por Diferentes Profissões
}

\section{Meanings of Tattoo's Consumption by Different Professions}

\author{
Weber Henrique Radael \\ Universidade Estadual de Maringá - UEM - Brasil \\ wradael@hotmail.com \\ ORCID: 0000-0001-6257-1894 \\ Flavia Mayara Segate \\ Universidade Estadual de Maringá - UEM - Brasil \\ flaviasegate@gmail.com \\ ORCID: 0000-0001-8278-1020 \\ Olga Maria Coutinho Pépece \\ Universidade Estadual de Maringá - UEM - Brasil \\ opepece@gmail.com \\ ORCID: 0000-0002-9155-9285 \\ Melissa Braga Nienkoetter \\ Universidade Estadual de Maringá - UEM - Brasil \\ ra102623@uem.br \\ ORCID: 0000-0002-5651-0048
}

Submetido em 06/08/2020; Aprovado em 24/08/2020.

\section{Resumo}

Objetivo do estudo: compreender o significado de consumo de tatuagens para diferentes profissionais nas áreas de exatas, humanas e saúde. Metodologia/Abordagem: pesquisa qualitativa descritiva na qual foram triangulados dados provenientes de entrevistas semiestruturas com 25 profissionais em formação de 11 cursos de graduação e entrevistas semiestruturadas com 5 profissionais responsáveis pela atividade de recrutamento e seleção. Principais resultados: os recrutadores de áreas mais tradicionais como saúde, direito e educação possuem receios na contratação de profissionais tatuados, sobretudo, os que irão ter um atendimento direto ao público. Porém, os profissionais em formação utilizam estratégias para não sofrerem tais repreensões sociais, principalmente, nas entrevistas de emprego. Contribuições acadêmicas: preconceito quanto ao uso de tatuagem ainda existente, na atualidade, confirma achados de pesquisas anteriores sobre o tema, demonstrando que apesar deste consumo ter se tornado mais comum, ainda conserva imagem de rebeldia e insubordinação. Contribuições práticas: fornece dados aos profissionais em formação que pretendem atuar em profissões mais conservadoras que posterguem o consumo de tatuagens em locais muito visíveis, no início de suas carreiras. Para profissionais de recrutamento e seleção, os achados indicam que tatuagens de temas polêmicos representam mais registros de superação de quem as consome do que de rebeldia. A característica de superação indica pessoas, em certa medida, mais resilientes e maduras emocionalmente o que pode servir como referência para ocupação de vagas que demandem essa característica. Porém atividades profissionais muito conservadoras requerem ainda cuidado na hora de contratar um profissional com tatuagens muito chamativas e expostas que realizará atendimento ao público.

Palavras-chave: Consumo; Recrutamento e seleção; Significado e Tatuagem.

\section{Abstract}

Purpose: To understand the consumption of the tattoos for different professional in the areas of Physical, Human and Health. Methodology/Approach: a descriptive qualitative research was carried out, using semi-structured interviews with 25 professionals in training from 11 different courses. To triangulate the data, semi-structured interviews were carried out with 5 professionals responsible for the Recruitment activity. Results: recruiters from more traditional areas such as Health, Law and Education are afraid to hire tattooed professionals, especially those who will have a direct service to the public. 
However, professionals in training use strategies to avoid suffering such reproofs, especially in job interviews. Academic Contributions: prejudice regarding the use of tattoos, which still exists even nowadays, confirms the findings of previous research on the subject, demonstrating that although this consumption has become more common, it retains an image of rebellion and insubordination. Practical Contributions: provides data to professionals in training, so that they intend to work in more conservative professions, so that they postpone the consumption of tattoos in very visible place at the beginning of their careers. For recruitment professionals, controversial tattoos represent more records of overcoming those who consume them than of rebellion. The overcoming characteristic indicates people who are, to a certain extent, more resilient and emotionally mature, which can serve as a reference for job vacancies that demand this characteristic. However, very conservative professional activities still require care when it comes to hiring a professional with very flashy tattoos exposed who will perform services to the public.

Keywords: Consumption; Recruitment and Selection; Tattoo' s meaning.

\section{Introdução}

Nas primeiras décadas do século XX, as tatuagens foram utilizadas para marcar pessoas marginalizadas como escravos ou criminosos. Nos campos de concentração nazista, prisioneiros também eram marcados com tatuagens, fazendo com que o consumo dessas fosse associado com algo negativo pela sociedade (Buss \& Hodges, 2017). Por outro lado, nesse mesmo período, também era possível encontrar pessoas que, por vontade própria, optavam por consumir tatuagens como é o caso de profissionais de algumas áreas, tais como: marinheiros, ferreiros, profissionais de circo (Rossi, 2011). Esses profissionais faziam uso das tatuagens para enaltecerem suas profissões e permitirem o reconhecimento destas. Nas situações anteriormente relatadas, tanto no caso de marcar para marginalizar quanto no caso de marcar para enaltecer a profissão, é possível verificar a capacidade das tatuagens de delimitarem fronteiras entre grupos sociais, discriminando quem pertence e quem não pertence a um grupo (Le Breton, 2000), por exemplo, os ferreiros que tinham um martelo tatuado, diferentemente dos sapateiros que tinham uma bota tatuada ou os criminosos que tinham desenhos diferentes atrelados aos diferentes crimes cometidos (Rossi, 2011).

Nas últimas décadas, já no século XXI, o consumo de tatuagem vem ganhando cada vez mais adeptos e dos mais diversificados perfis, ficando defasada a associação do consumo de tatuagem exclusivamente a grupos marginalizados. De acordo com uma pesquisa realizada pela revista Super Interessante, com 80 mil pessoas em 2013, no Brasil, é visível o grande número de pessoas consumidoras de tatuagem no mundo. Em nosso país, apesar de não existir ainda um censo oficial, um estudo do Sebrae, realizado entre 2016 e 2017, mostra que o setor cresceu em média 24,1\% (Sebrae, 2018). Já outro estudo realizado, em 2019, pelo Instituo Alemão Dalia, aponta o Brasil como 9o país no ranking entre os países mais tatuados do mundo, com 38\% da população com tatuagens (Bayer Jovens, 2019). Neste contexto, as tatuagens se popularizaram e, portanto, imagina-se que foram ressignificadas, deixando de ser percebidas como negativas. Considerando historicamente o consumo de tatuagens associado a profissões específicas, pressupõe-se que com o aumento de pessoas tatuadas também tenha aumentado a variedade de profissões nas quais se encontram tatuados e pressupõe-se, ainda, que esse aumento tenha levado a uma ressignificação das tatuagens, influenciando na relação entre os empregadores e os profissionais tatuados. Assim, estabeleceu-se como objetivo geral, neste artigo, compreender o significado de consumo do ato de tatuar o corpo para diferentes subgrupos profissionais nas áreas de exatas, humanas e saúde e sua influência na hora do recrutamento e seleção de profissionais no mercado de trabalho.

Sabe-se que a aparência do profissional interfere na sua contratação - vide importância da vestimenta para o processo seletivo que inclusive é discutida em estudos na área de administração de recursos humanos (Carvalho \& Grisci, 2003). Uma pesquisa realizada por Daniel Hamermes afirma que pessoas consideradas bonitas possuem mais sucesso na carreira e pesquisa da College of Optometrists_argumenta que a utilização de óculos interfere na percepção profissional do recrutador diante do candidato, e, também, na manutenção do profissional na sua ocupação (Exame, 2011). Segundo Jones, empresário britânico, CEO da empresa Dragons, metade dos executivos britânicos reconheciam ter deixado de promover ou aumentar salários e até realizar demissões de funcionários devido às vestimentas utilizadas, tais como: decotes e roupas curtas (Exame, 2011). Pensando na influência da aparência do profissional para a sua carreira, do aumento do consumo de tatuagens nas últimas décadas e do papel da 
tatuagem na composição da aparência dos profissionais, realizou-se a presente pesquisa qualitativa com entrevistas a 25 profissionais em formação nos cursos de Comunicações e Multimeios, Química, Enfermagem, Educação Física, Matemática, Pedagogia, Física, História, Artes Cênicas e Geografia e a cinco profissionais de empresas de recrutamento e seleção.

0 presente artigo encontra-se composto pelas seguintes seções: revisão teórica, procedimentos metodológicos, perfil dos profissionais em formação entrevistados (Exatas, Humanas e Saúde), perfil dos profissionais em recrutamento e seleção, discussão dos resultados separados por profissionais em formação e profissionais de recrutamento e seleção, por fim, as conclusões do estudo.

\section{Revisão teórica: Tatuagens, relações sociais e profissões}

Estudar o consumo de tatuagens envolve investigar diversos fatores desde a escolha do tatuador, do tamanho do desenho, do local no qual o desenho será feito, o que irá influenciar diretamente no preço e no tempo para que a tatuagem seja feita, ao objetivo que o consumidor da tatuagem busca ao tatuarse. Dentre os fatores mencionados, o mais complexo diz respeito à seleção do desenho que será tatuado. Isso porque o desenho das tatuagens engloba diversos significados que resultam em variadas funções que permitirão ao tatuado alcançar seus intuitos ao consumir a tatuagem.

Zestcott et al. (2018) evidenciam a existência de estigmas relacionados a tatuagens na atualidade, os quais estão ligados à violação de normas e padrões culturais. Seus resultados apontam que indivíduos com tatuagens foram vistos como menos valorizados em relação àqueles sem tatuagens, no que diz respeito a diversos aspectos como atléticos, profissionais, atrativos e agradáveis, bem como mais promíscuos, perigosos e propensos a vícios. Por outro lado, os indivíduos tatuados também são vistos como mais corajosos, que buscam por emoções e beleza, além de serem mais artísticos. Os autores relatam que ambientes legais, empresariais e de saúde são espaços que mais apresentam atitudes implícitas e explícitas de preconceito, estereotipagem, discriminação e preferências por não tatuados. Por este motivo, ainda existe a tendência de esconder os desenhos, apesar da prevalência generalizada de indivíduos tatuados (Zestcott et al., 2018).

Kalanj-Mizzi, Snell e Simmonds (2018) apresentam que aqueles com múltiplas tatuagens são mais propensos a serem vulneráveis ao estigma e à discriminação. Os autores complementam que os indivíduos com tatuagens únicas podem ter motivações transitórias, já os indivíduos com múltiplas tatuagens permanecem com um compromisso repetido. Assim, define-se múltiplas tatuagens como "três ou mais tatuagens distintas ou que tenha participado de vários procedimentos com o tatuador para completar uma grande área do corpo" (Kalanj-Mizzi et al., 2018, p. 2).

Importante ressaltar a diferença de 'pessoas tatuadas' de 'pessoas com tatuagem', pois os motivos para aqueles com tatuagens individuais podem ser diferentes para aqueles com várias tatuagens, e aqueles com várias tatuagens são mais visíveis, estando expostos à maior discriminação (Bell, 1999; Roberts, 2012).

Para Patterson (2018), a função da tatuagem altera-se conforme cada cultura focaliza este artefato, ou seja, se um povo entende os desenhos como objetos, a tatuagem passa a ter função decorativa. Contudo, ela sempre será carregada de significados pessoais que passam de mera decoração, sendo um meio de expressão criativo e indicação de gosto.

Conforme Zestcott et al. (2018), as percepções de pessoas não tatuadas em relação a pessoas tatuadas levam em conta o desenho, bem como a demografia do observador, ou seja, idade, sexo, classe social, além da cultura e de experiências íntimas de cada um e, até mesmo, posições políticas e ideológicas.

Quanto ao estigma de ser tatuado, o local do corpo que mais provoca discriminação social é o rosto (Rossi, 2011). Segundo Le Breton (2004), as tatuagens no rosto são estigmas voluntários.

Deste modo, Larsen, Patterson e Markham (2014) afirmam que indivíduos tatuados adotam estratégias para não sofrerem repreensões ou exclusões sociais que estão relacionadas a um estereótipo de beleza e modelo de moral. Tais estratégias são mecanismos que os protegem de consequências negativas da estigmatização, tais como:

- Manipulação das autopercepções: Esforços em equilibrar as tatuagens com a estética convencional, como tipo de roupas, cabelo, sapatos, feminilidade ou masculinidade.

- Manipulação da percepção de outros: Criar histórias e significados que justifiquem a decisão por tatuar-se. Tais justificativas podem mudar conforme o ambiente ou grupo em que o indivíduo se encontra. 
- Múltiplas identidades: Tatuar locais do corpo que permitam a ocultação do desenho, permitindo ao indivíduo seguir estereótipos mais comuns ou não, conforme lhe convém.

Deste modo, fica evidente a infinidade de interpretações e funções que um mesmo desenho pode representar para o indivíduo tatuado e para outros. No entanto, Patterson (2018) afirma que raramente se pode controlar os significados atribuídos pelos outros aos desenhos e ao ato de tatuar-se. Ainda assim, indivíduos tatuados enfrentam a maneira estigmatizada como a tatuagem é interpretada por diferentes pessoas e culturas e continuam a modificar os corpos e contar suas histórias em sua própria pele.

Por ter um consumo milenar, as tatuagens receberam diferentes significados e funções para os indivíduos ao longo dos tempos. Diante das constantes mudanças na interpretação e função dos desenhos em corpos tatuados, a tatuagem se difundiu às práticas cotidianas de produção e consumo, tornando-se cada vez mais popular. Seu significado passou a ter natureza mutável, envolvendo uma complexa teia de relações sociais, políticas, econômicas e culturais (Larsen, Patterson \& Markham, 2014).

Sobre profissões e tatuagens, Le Breton (2000) identificou que os próprios tatuados alegam que, se tivessem como profissão atividades mais tradicionais como as de médico ou advogado, não teriam se tatuado, por acharem incongruente uma tatuagem em um profissional com estas ocupações: "o corpo é nas nossas sociedades um fator de individualização, modificando-o modifica-se a sua relação com o mundo. Para mudar de vida, modifica-se o corpo, ou pelo menos tenta-se" (p. 186).

Caroni e Grossman (2012) afirmam que o uso de tatuagens e piercings são associados por profissionais da saúde com ideias negativas como desvio de conduta, rebeldia, apelo erótico, uso de entorpecentes, entre outros devido, provavelmente, à criação a qual se caracteriza pela presença de alguns preconceitos pré-estabelecidos por sua família e religião.

Esta visão negativa pode tornar pessoas com marcas corporais alvos de uma visão negativa de profissionais de saúde ao procurar atendimento (Stuppy et al., 1998), além disso, gerar dúvidas a respeito da credibilidade e competência profissional do sujeito (Caroni \& Grossman, 2012).

Ao comparar os candidatos com seu perfil e suas características diante das pré-estabelecidas para o cargo, estudos recentes na área de recursos humanos indicam que a aparência tem papel importante para a seleção (Pedro \& Aguiar, 2016).

Busca-se o "perfil ideal" para a vaga, pré-estabelecendo, então, um estereótipo para tal, do qual a aparência aparece como um dos pré-requisitos, criando, destarte, uma expectativa (Negri, 2011). De acordo com estudos na área de recursos humanos, as tatuagens apresentam um papel importante e muitas vezes decisivo na composição do "perfil ideal" e na seleção do candidato (Barbosa, Brito \& Bizarria, 2016; Morais, Morais \& Rugai, 2019; Pedro \& Aguiar, 2016; Rosário, 2008; Silva \& Saraiva, 2014).

\section{Método}

Partindo do objetivo geral de compreender o significado do consumo de tatuar o corpo para diferentes subgrupos profissionais nas áreas de exatas, humanas e saúde, optou-se pela pesquisa qualitativa, considerando-a mais apropriada para este estudo. A pesquisa qualitativa permite responder questões muito particulares, atentando para um nível de realidade que não pode ser quantificado e que se expressa por meio de crenças, significados, valores, isto é, um nível de entendimento mais profundo das relações e dos fenômenos (Minayo et al., 2002). 0 método utilizado foi o descritivo. Por apresentar características de uma situação, grupo ou indivíduo específico, buscou-se entender melhor as especificidades dos subgrupos estudados e aprofundar o tema, sem a preocupação de explicação (Selltiz, et al., 1975; Vergara, 2000).

A população do estudo deve possuir as características ou conjunto de elementos que serão o objeto do estudo (Vergara, 2007). Assim, a população é composta pelos subgrupos dos profissionais em formação nas áreas de Ciências Exatas, Ciências Humanas e Ciências da Saúde. Selecionou-se Ciências da Saúde por ser uma área na qual os profissionais percebem uma maior resistência aos tatuados (Caroni \& Grossman, 2012). Já a área das Ciências Humanas por ser um campo mais aberto às discussões e questionamentos dos padrões e das estruturas sociais, assim como por se perceber um número maior de estudantes tatuados nessa área na universidade pesquisada. E as Ciências Exatas por ser uma área mais técnica e com grande número de simbologias, tais como: fórmulas e equações e por ter a possibilidade de identificar se tais simbologias são transpostas para o consumo de tatuagens.

Dentre essas grandes áreas, obteve-se como sujeitos de pesquisa os profissionais em formação dos cursos de Artes Cênicas, Comunicação e Multimeios, Educação Física, Enfermagem, Física, Geografia, 
História, Matemática e Química da Universidade Estadual de Maringá (UEM); e, por profissionais da área de Recursos Humanos - recrutamento e seleção.

A coleta de dados realizou-se por meio de entrevistas semiestruturadas com os profissionais em formação, pois estas partem de questionamentos apoiados na teoria, mas permitem oferecer um amplo campo de interrogativas que vão surgir conforme as respostas dos entrevistados, possibilitando a eles discorrerem sobre o tema (Triviños, 1987; Minayo, 2009).

Para dar um maior rigor ao estudo, realizou-se dois testes pilotos. Um primeiro teste piloto foi realizado com três profissionais em formação de Comunicação e Multimeios para conferir se as perguntas da entrevista semiestruturada estavam adequadas ao objetivo da pesquisa. 0 segundo teste piloto constitui-se em entrevista de um profissional em formação de cada área (exatas, humanas e saúde) para analisar se estas precisariam ser personalizadas para as diferentes áreas.

Com a entrevista semiestruturada reajustada, após as seis entrevistas de testes, buscou-se entrevistar os profissionais em formação até encontrar repetição de discurso nos achados do campo. Segundo Minayo (2017), a saturação se materializa quando as entrevistas se repetem sem trazer revelações que podem indicar novas inferências, ou seja, quando se encontra a lógica interna do objetivo da pesquisa, mesmo que provisoriamente. Diante deste aspecto, foram realizadas um total de 25 entrevistas, conforme o anexo 1.

Conforme Minayo (2017), o conceito e aplicação da saturação é discutido metodologicamente no campo científico. A autora apresenta visões de outros pesquisadores referente ao tamanho da amostra para pesquisas qualitativas, em geral, serem consideradas suficientes e fidedignas, tais como: 10 entrevistados para Atran, Medin e Ross (2005) e 20 a 30 entrevistados para Morse (1994) e Creswell (1998). Portanto, atribui-se, também, uma confiabilidade ao tamanho da amostra do estudo mediante os autores apresentados.

Os pesquisadores obtiveram acesso aos entrevistados por três maneiras distintas. Primeiro, indo diretamente ao bloco dos cursos e perguntando quem tinha tatuagem e gostaria de participar da pesquisa. Segundo, identificando entrevistados conhecidos dos próprios pesquisadores. E terceiro, acolhendo outros entrevistados que foram indicados por entrevistados.

As coletas dos dados dos profissionais em formação foram realizadas entre os meses de setembro a dezembro de 2019, com um total de 25 entrevistados, gerando 339 minutos de gravação e 81 páginas de transcrição. As entrevistas com os cinco profissionais da área de recrutamento e seleção de Recursos Humanos foram realizadas nos meses de junho e julho de 2020, por meio da plataforma Skype e geraram 71 minutos e 47 segundos de gravação e 17 páginas de transcrição e foram realizadas no mês de julho de 2020.

Os dados coletados foram analisados por meio da análise de conteúdo (Caregnato \& Mutti, 2006). 0 estudo busca validade mediante dois tipos diferentes de triangulação conforme apresentado por Zappellini e Feuerschutte (2015). A triangulação de investigadores: cada pesquisador realizou a análise e depois essas análises foram confrontadas e comparadas entre os quatros pesquisadores do estudo. A triangulação de fontes de dados: realizou-se a entrevista em dois subgrupos distintos (profissionais em formação de três diferentes áreas) para o cruzamento dos dados e acrescentou-se entrevistas com 5 profissionais de recrutamento e seleção.

\section{Análise dos dados}

A seguir encontra-se uma breve descrição dos perfis dos entrevistados por área, na sequência a discussão referente aos profissionais em formação, seguida pela descrição do perfil profissionais de recrutamento e seleção entrevistados, finalizando esta seção, encontra-se a discussão referente aos profissionais de recrutamento e seleção em RH.

\section{- Área de humanas}

Na área de Humanas, foram entrevistadas 10 profissionais em formação, sendo: cinco do curso de Comunicação e Multimeios, uma de História, três de Geografia e uma de Artes Cênicas, com idades entre 18 e 25 anos, com a primeira tatuagem entre 17 e 18 anos, sendo seis mulheres e quatro homens.

Diferentemente das outras duas áreas cujos maiores números de tatuagens nos entrevistados foram oito, na área de humanas, os números são maiores. Nela, há um entrevistado com 30 tatuagens (entrevistado 13).

Os desenhos observados também foram diferentes, nas demais áreas de formação, encontram-se 
mais flores, frases e homenagens. Na área de humanas, observou-se desenhos mais incomuns como flor de maconha, mulher segurando um bebê portando uma arma, bode, animes, animais, desenhos feitos pela própria tatuada, escrita ao inverso, cérebro e outras. Observou-se tatuagens com flores, frases e homenagens, mas em menor escala.

Os locais tatuados foram mais diversos, apresenta-se tatuagens no peito, nas costas, nas coxas, nas nádegas e em lugares mais aparentes como mão, pescoço e antebraço. Além disso, as tatuagens são maiores no tamanho, quando comparadas às outras duas áreas pesquisadas.

\section{- Área de exatas}

Foram entrevistados sete profissionais em formação da área de Exatas na Universidade Estadual de Maringá (UEM), sendo: quatro do curso de Química, dois do curso de Matemática e um do curso de Física. Os profissionais em formação entrevistados têm idade entre 21 e 35 anos e a primeira tatuagem foi realizada entre 15 e 28 anos de idade. Desses, cinco são do sexo feminino e dois do sexo masculino.

No curso de Química, uma entrevistada possui uma tatuagem relacionada diretamente ao curso: a 'estrutura química da Dopamina' (que é o neurotransmissor da sensação de felicidade, prazer e amor), que foi feita quando estava no terceiro ano do curso (21 anos). Esta entrevistada tem 22 anos de idade e realizou sua primeira tatuagem com 18 anos, possui três tatuagens no total com tamanhos médios a grande, sendo duas nas costas e uma na costela. A entrevistada relatou que fez a tatuagem sem intenções de escondê-las. Mas, quando precisa, por motivos profissionais, consegue esconder por não estar em regiões muito expostas como rosto, mãos e pescoço.

Outra entrevistada do curso de Química que realizou sua primeira tatuagem com 18 anos possui quatro tatuagens no total. Ela não possui nenhuma tatuagem relacionada ao curso como a entrevistada anterior, mas quando estava no quarto ano da faculdade tatuou um globo mundial no antebraço direito. Ela relatou que o significado dessa tatuagem representou um momento que estava se sentindo perdida e insatisfeita com o curso e tatuou o globo mundial para representar que o "mundo" está nas mãos dela. Ao ser questionada sobre assuntos profissionais, informa que cobre todas as tatuagens usando um jaleco quando ela dá aula no Estágio de Docência em uma escola pública da cidade e informa que, como ainda não foi contratada como efetiva para atuar em uma instituição de ensino, acha melhor cobrir as tatuagens durante o trabalho.

Duas outras entrevistadas apresentaram tatuagens específicas relacionadas com o curso que estão fazendo, essas duas são do curso de Matemática. A primeira tem 25 anos de idade e fez sua primeira tatuagem com 15 anos, hoje possui 4 tatuagens ao total. 0 desenho que representa o curso de Matemática é a figura do cálculo da 'Integral', pois a conta da 'Integral' tende ao infinito e tem como significado para ela que o amor tende ao infinito. Ela fez essa tatuagem, em específico, para representar o curso que ela estava fazendo, que é Matemática.

A segunda entrevistada com tatuagem relacionada ao curso fez uma equação matemática na mão direita seis meses após entrar no curso de Matemática, tinha 17 anos de idade. Ela relata que o significado da tatuagem da equação representa a educação como uma forma de mudar o mundo e queria fazer uma tatuagem que tivesse ligação com seu curso.

Os entrevistados demonstraram uma preocupação em colocar tatuagens em lugares muitos expostos, por medo de sofrerem algum tipo de "punições", no momento de procurar emprego. Observou que uma tática utilizada é cobrir as tatuagens quando participam de entrevistas com o empregador.

\section{- Área da saúde}

Já da área de Saúde foram entrevistados nove profissionais em formação, sendo: três de Biomedicina, três de Educação Física, duas de Enfermagem e uma de Farmácia. Possuem idade entre 20 e 30 anos, com a primeira tatuagem entre 14 e 29 anos, sendo um do sexo masculino e as demais do sexo feminino.

Uma entrevistada do curso de Biomedicina tem em seu braço a frase "Non-stop the innovation" com o desenho de um microscópio, um DNA e uma célula em divisão. Essa tatuagem foi feita quando passou no vestibular e remete a seu curso e sua crença na ciência. 0 entrevistado de Educação Física possui na costela luvas de box tatuadas, remetendo seu esporte favorito que o levou à escolha do curso.

No entanto, os outros entrevistados não possuem tatuagens relacionadas diretamente ao seu curso ou à área da saúde, e sim a crenças pessoais, desenhos que gostaram, autodescrição, tatuagens junto com pessoas que estimam ou homenagens. 
No ambiente de trabalho, os profissionais em formação de Educação Física não demonstraram receio nem resistência ou dificuldades no mercado devido a tatuagens, dizendo que, nesta área, as tatuagens são comuns e não se constituem um empecilho.

Já nos cursos de Biomedicina, Farmácia e Enfermagem a relação entre mercado de trabalho e tatuagens foi oposta, apresentando as tatuagens como empecilho nas contratações. Os entrevistados afirmaram que as escondem onde estagiam e que, ao realizar a tatuagem, pensam em um local no qual o jaleco possa cobri-la.

O profissional em formação de Educação Física possui uma tatuagem dos personagens do desenho "Rick e Morty" e relatou julgamentos negativos em relação a ela, pois estes personagens aparecem no desenho consumindo muito álcool, drogas e coisas que não são benéficas para a saúde indo no caminho contrário à sua profissão. Por outro lado, explicou que gosta muito da visão de mundo diferenciada que estes personagens apresentam. Afirmou também que tatuagens que são relacionadas a atitudes não benéficas à saúde podem ser malvistas em sua área.

Os profissionais em formação na área de saúde apresentaram desenhos de todos os tamanhos, coloridos e em preto e branco, em diversas áreas do corpo como perna, braço, antebraço, coxa, atrás da orelha, costelas, entre outros lugares. Mas não apresentaram nenhuma tatuagem em lugar como pescoço, rosto e mãos. Diversos entrevistados afirmaram que estes locais podem ser extremamente mal julgados pela sociedade, trazendo um preconceito muito grande.

\section{- Discussão referente aos profissionais em formação}

Diversos cursos nas três áreas pesquisadas (Exatas, Humanas e Saúde) possuem formação em licenciatura. Foi percebido-se que todos os entrevistados que pretendem seguir a carreira de docência afirmaram que as tatuagens em locais expostos podem ser um empecilho na contratação, principalmente para o ensino particular. As falas a seguir apresentam essas afirmações quando questionado se a tatuagem poderia causar algum impedimento na profissão:

"Pode sim, pois como eu quero ser professora, hoje está bem menos, preconceito nisso, mas em colégio particular, por exemplo, tem muitos que ainda não aceitam" (Entrevistada 5).

\footnotetext{
"Depende, se eu for para um colégio privado, provavelmente, dependendo da filosofia do colégio, pode ser que sim" (Entrevistado 1).

"Sim, porque quero ser professora" (Entrevistada 2).
}

Isso ocorre porque a contratação da rede privada baseia-se muito na entrevista realizada pessoalmente, por isso, a opinião do entrevistador em relação ao candidato possui uma grande influência. As instituições procuram formar uma forte imagem de responsabilidade, transparência, confiança, e também uma identidade que se pareça com a forma de educar muito semelhante à dos pais, portanto, a busca do "perfil ideal" é muito buscada (Negri, 2011). 0 grande problema das tatuagens é a correlação delas com perfis promíscuos, perigosos e propensos a vícios, assim como colocado por Zestcott et al., (2018), tornando, então, o indivíduo tatuado longe do "perfil ideal" adequado para a instituição.

Para a área da saúde, todos os cursos acreditam que a tatuagem influencia muito em diversos âmbitos dentro da profissão, principalmente com o atendimento ao público, por abranger pessoas de diferentes pensamentos e crenças. Assim, a necessidade de confiança que pode ser quebrada ao ver a tatuagem, considerando seu portador de caráter duvidoso, como afirmam Caroni e Grossman (2012).

"Porque tem que esconder piercing também, porque eles falam que a gente lida com todo e qualquer tipo de paciente e pra evitar qualquer coisa (preconceito), eles pedem pra esconder" (Entrevistada 23).

A falta de higiene também foi correlacionada com a existência de modificações corporais, tanto pela aparência externa quanto por possíveis riscos de contaminação e infecções contraídas no ato da modificação. Como apresentado no estudo de Stuppy et al. (1998), a tatuagem provoca uma visão negativa tanto para os profissionais, quanto para pacientes ao serem atendidos, podendo até serem atendidos de forma diferente por possuírem piercings e tatuagens.

"Eu senti preconceitos mais por parte de familiares distantes e no hospital também, dependendo também o setor que nós estamos, nunca ninguém falou nada, mas eles olham né. Nunca sofri com isso (preconceito), só recebi olhares feios" (Entrevista 21).

Como discutido por Larsen, Patterson e Markham (2014), os indivíduos tatuados adotam 
estratégias para não sofrerem as repressões. 0 ato de esconder as tatuagens com as vestimentas com golas e mangas longas no local de trabalho e em entrevistas de empregos foi muito citado:

"Fiz em um local escondido para não ter que lidar com o preconceito diretamente, nem me atrapalhar no emprego" (Entrevistada 25).

"Eu estou desempregada, mas quando fui fazer entrevista de emprego escondi todas, coloquei gola alta, blusa, para não mostrar nada, porque no ambiente de trabalho é complicado. Também, acho que pessoas muito religiosas não aceitam bem tatuagens, sinto que tem mais resistência deles" (Entrevistada 7).

"Do feminismo, eu fiz um pouco mais escondido porque infelizmente na sociedade que a gente vive dependendo do emprego, por exemplo, algum homem não gosta, e me desqualifica da vaga por isso, por exemplo, e como era uma coisa muito pessoal foi a tatuagem que eu mais quis fazer. Aí, eu optei por fazer uma coisa bem mais pessoal mesmo, e no quadril só dá para ver quando eu estou de biquíni, no dia a dia ninguém consegue ver" (Entrevistada 22).

"Escondo geralmente quando eu tenho aula nas UBS (Unidade Básica de Saúde). Mas, aí também eu estou de jaleco ou quando eu tenho que atender no LEPAC (Laboratório de Ensino e Pesquisa em Análises Clínicas da UEM), aí eu tenho que esconder" (Entrevistada 23).

“Às vezes, eu tenho que usar o jaleco mais fechado, não ir tanto com roupas mais curtas. Eu sempre tampo pelo menos as dos braços. Eu não me sinto com vergonha, me sinto muito bem com as minhas tatuagens, mas tem esses momentos" (Entrevistada 4).

Segundo Le Breton (2000), as tatuagens no rosto e pescoço apresentam-se como um estigma voluntário e com maior discriminação. Quando questionados em quais locais não tatuariam, os entrevistados afirmaram rosto e alguns rosto e pescoço:

“O rosto e o pescoço (...) por causa do emprego, acho que ficaria difícil e arrumar emprego e a sociedade já quase não aceita no corpo imagina no rosto" (Entrevistada 23).

"Eu acho que não tatuaria o rosto pelo preconceito que ainda tem e porque eu também não acho um lugar bonito e tal, por estética mesmo" (Entrevistada 24).

A grande exceção foi o curso de Educação Física, no qual todos os entrevistados afirmam que as tatuagens não possuem efeito negativo diante do mercado de trabalho, inclusive é bem comum tatuagens grandes e em locais visíveis. Zestcott et al. (2018) apresentam em seu estudo a tatuagem como uma questão de força e coragem, devido a seu ritual dolorido e exposição de ideias. Estes traços são constantemente encontrados nos profissionais em formação de Educação Física, força e coragem para enfrentarem os desafios físicos da profissão, podendo então associar a não estigmatização da tatuagem nesta área.

"Quase todo mundo que conheço do curso tem grandes tatuagens e bem à mostra" [...] "não escondo porque não são um problema na hora da contratação" (Entrevistada 19).

“Na academia em que faço estágio quase todo mundo tem, é até anormal quem não tem, principalmente na parte destinada a lutas" (Entrevistado 18).

Apesar da tatuagem não apresentar caráter de estigma nesta profissão, todos os entrevistados afirmaram que não tatuariam o rosto, devido ao preconceito da sociedade e por não considerem esteticamente bonito.

Segundo Zestcott et al., (2018), pessoas tatuadas são consideradas mais artísticas e criativas. Le Breton (2000) argumenta que profissões mais tradicionais tendem a estigmatizar mais as tatuagens. Uma entrevistada afirmou que uma opção de curso era Direito e sabia que se optasse por ele não poderia ter suas tatuagens à mostra. Porém, estudantes de Artes Cênicas, apesar de afirmarem que a maioria de seus colegas do curso possuem muitas tatuagens e as utilizam como forma de expressão artística, ao tentarem inserção no mercado de trabalho. ainda escondem suas tatuagens com muitas roupas e golas altas com medo do preconceito.

\section{- Profissionais de recrutamento e seleção}

Foram entrevistados cinco responsáveis por recrutamento e seleção em suas empresas, sendo cinco mulheres atuantes em: 1) prestadora de serviços financeiros, administrativos e jurídicos; 2) farmacêutica; 3) publicitária; 4) advogada e 5) psicóloga. 
As entrevistadas responsáveis por recrutamento e seleção atuam em empresas de contabilidade, distribuição de medicamentos hospitalares, escritório de advocacia, imobiliária, rede de supermercados e grupo que abrange empresa rural, construção e policlínicas médicas populares. Todos são locais que, teoricamente, poderiam contratar profissionais das três áreas elencadas nesta pesquisa (Exatas, Humanas e Saúde). As profissionais em recrutamento e seleção possuem idades entre 28 a 50 anos, atuando de 2 a 19 anos na profissão, conforme apresentado no Quadro 1.

Quadro 1: Perfil das profissionais responsáveis pelo recrutamento e seleção.

\begin{tabular}{|c|c|c|c|c|c|c|c|}
\hline Entre. & $\begin{array}{l}\text { Gê- } \\
\text { nero }\end{array}$ & Idade & $\begin{array}{l}\text { Ramo da } \\
\text { Empresa }\end{array}$ & Cargo & $\begin{array}{c}\text { Tempo } \\
\text { na Pro- } \\
\text { fissão }\end{array}$ & $\begin{array}{c}\text { Formação } \\
\text { Acadê- } \\
\text { mica }\end{array}$ & Percepção sobre tatuagens \\
\hline RH1 & $\mathrm{F}$ & 25 & $\begin{array}{l}\text { Administra- } \\
\text { tivo }\end{array}$ & $\begin{array}{l}\text { Encarre- } \\
\text { gado de RH }\end{array}$ & 5 anos & $\begin{array}{l}\text { Estudante } \\
\text { de Psicolo- } \\
\text { gia }\end{array}$ & $\begin{array}{l}\text { Há restrição para contratação; o } \\
\text { estereótipo do profissional admi- } \\
\text { nistrativo não envolve tatuagens; } \\
\text { tatuagens estão relacionadas à } \\
\text { informalidade. }\end{array}$ \\
\hline RH2 & $\mathrm{F}$ & 34 & $\begin{array}{l}\text { Farmacêu- } \\
\text { tico }\end{array}$ & $\begin{array}{l}\text { Farmacêu- } \\
\text { tica Res- } \\
\text { ponsável }\end{array}$ & 10 anos & Farmácia & $\begin{array}{l}\text { Há poucas restrições; tatuagem } \\
\text { está relacionada à juventude e } \\
\text { pessoas mais velhas possuem } \\
\text { mais credibilidade que pessoas } \\
\text { jovens, na área da saúde; tatua- } \\
\text { gens em pescoço e rosto reme- } \\
\text { tem à rebeldia e insubordinação. }\end{array}$ \\
\hline RH3 & $\mathrm{F}$ & 50 & Jurídico & $\begin{array}{l}\text { Advogada } \\
\text { Responsá- } \\
\text { vel }\end{array}$ & 16 anos & Direito & $\begin{array}{l}\text { Há muita restrição para contrata- } \\
\text { ção; o estereótipo do profissional } \\
\text { jurídico não envolve tatuagens; } \\
\text { tatuagens estão relacionadas à } \\
\text { informalidade, irresponsabili- } \\
\text { dade e não seriedade. }\end{array}$ \\
\hline RH4 & $\mathrm{F}$ & 28 & $\begin{array}{l}\text { Supermer- } \\
\text { cadista }\end{array}$ & $\begin{array}{l}\text { Psicóloga } \\
\text { Responsá- } \\
\text { vel }\end{array}$ & 3 anos & Psicologia & $\begin{array}{l}\text { Há restrições; tatuagens podem } \\
\text { não ser aceitas pelos clientes; ta- } \\
\text { tuagens em pescoço e rosto re- } \\
\text { metem à rebeldia e violência. }\end{array}$ \\
\hline RH5 & $\mathrm{F}$ & 30 & $\begin{array}{l}\text { Clínica mé- } \\
\text { dica Imobi- } \\
\text { liária Agro- } \\
\text { pecuária }\end{array}$ & $\begin{array}{l}\text { Publicitária } \\
\text { Responsá- } \\
\text { vel }\end{array}$ & 6 anos & $\begin{array}{l}\text { Publici- } \\
\text { dade }\end{array}$ & $\begin{array}{l}\text { A restrição maior são tatuagens } \\
\text { no rosto e pescoço para empresa } \\
\text { Imobiliária e Agropecuária. Mas, } \\
\text { Clínica Médica e profissionais } \\
\text { com atendimento direto ao cli- } \\
\text { ente nas três empresas têm res- } \\
\text { trições; tatuagens estão relacio- } \\
\text { nadas à incredibilidade. }\end{array}$ \\
\hline
\end{tabular}

\section{- Discussão referente aos profissionais de recrutamento e seleção em RH}

Todas as profissionais responsáveis pelo recrutamento e seleção das empresas afirmaram que, para serviços internos em que não há contato direto com o cliente, as tatuagens não seriam um estigma. Mas, para cargos que possuem contato com o cliente, seriam um aspecto decisório negativo, pois ao lidar com clientes de diferenças crenças, idades e personalidades, a tatuagem poderia causar estranhamento e até perda do fechamento do negócio, corroborando os resultados de Caroni e Grossman (2012) nos quais a tatuagem pode conferir um caráter duvidoso ao profissional.

Para o escritório de advocacia, a profissional entrevistada (RH3) afirmou que pessoas com tatuagens visíveis não são contratadas. Confirmou, também, que os tatuados apresentam uma percepção mais violenta, com características aparentes de antiprofissionais e menos confiáveis. A entrevistada relata que tatuagens pequenas e discretas como cruzes ou flores no pulso são aceitas, mas outras não. Afirmou que o ramo jurídico não aceita tatuagens nem demais modificações corporais como piercings e cabelo colorido, por ser um ramo extremamente conservador onde somente ternos, gravatas e roupas com cores neutras são aceitas e por possuir diversas exigências de aparências como a obrigatoriedade de utilização de toga e código de vestimenta para o fórum e tribunal.

A entrevistada RH3 acrescentou sobre serem estigmatizados até nas gravatas com cores não 
neutras, ou seja, sendo malvistos os profissionais que usam cores muito vivas. Em seu escritório, é obrigatório o uso de terno e gravatas para homens e roupas sociais como blazer e vestidos sociais para mulheres, precisando estar sempre com cabelo cortado e alinhado, e unhas feitas para mulheres. Explicou sobre esta ser a liturgia do cargo, ou seja, o código de vestimenta que é esperado para um advogado, ao qual Carvalho e Grisci (2003) apresentam a importância das vestimentas nas profissões para reafirmarem a aparência de profissional competente.

O código de vestimenta, as cores e o posicionamento, segundo a empresária, passam uma imagem de confiança, sobriedade e seriedade dos advogados para os clientes. Complementou que, caso seus advogados fizessem apenas serviços internos, talvez as modificações corporais não fossem um grande problema, mas como todos seus colaborados fazem serviços internos e externos, precisam estar com a aparência esperada pela sociedade para um advogado. Sobressaltou que inclusive os estagiários devem vestirem-se assim, portanto, remetendo aos profissionais em formação. A entrevistada RH3 argumenta que todos que têm contato com os clientes como secretarias e recepcionistas precisam ter uma boa vestimenta e boa aparência, concluindo que apenas as faxineiras e office boys não precisam estar vestidos a caráter. Ambas as profissionais entrevistadas, RH2 e RH5, que lidam com a área da saúde afirmam que há um grande preconceito por médicos e por demais profissionais em relação às tatuagens, por isso evitam contratar pessoas com diversas tatuagens, confirmando, aqui, a preocupação relatada nas entrevistas dos profissionais em formação.

A publicitaria (RH5) que cuida do grupo com as três empresas nas áreas Clínica Médica, Imobiliária e Agropecuária trabalhava em São Paulo e relata que, em sua antiga empresa, o uso e exposição de tatuagens era encorajado, e por terem um contato mais estreito com agências de marketing e publicidade, por isso acredita que as tatuagens não apresentavam nenhuma diferenciação entre profissionais tatuados e não tatuados. Porém, por atuar atualmente em uma cidade do interior mais provinciana e tradicional, sequer entrevistou alguém com muita tatuagem e teria receio em contratar pessoas tatuadas para fazerem contato com os clientes, e também, em sua empresa de clínicas médicas, principalmente, em áreas como pescoço e rosto. Como apresentado por Caroni e Grossman (2012), a saúde é uma área na qual os profissionais percebem uma maior discriminação ao terem tatuagens.

A entrevistada RH1 da área administrativa afirmou que ao descobrir que uma recém contratada tinha diversas tatuagens no braço, ela e seu gerente reduziram suas expectativas em relação ao profissionalismo e execução da funcionária no cargo. Porém, apresenta que "esta funcionária superou as expectativas, mas caso ela não tivesse escondido sua tatuagem na entrevista provavelmente não seria contratada". Ela ainda informa que pessoas que escondem suas tatuagens na hora da contratação são malvistas por tentarem esconder uma parte de sua personalidade.

Os desenhos também foram comentados pelas profissionais de recrutamento e seleção. Todas afirmaram que desenhos de cunho muito religioso, de monstros, muito coloridos ou com simbologias racistas causam um grande estranhamento, impedindo, então, a contratação. Em relação ao local tatuado, áreas como pescoço e rosto foram apontadas como um requisito para não contratação por todas as entrevistadas, devido ao receio que os clientes poderiam apresentar.

Portanto, todas as profissionais entrevistadas apontaram a estigmatização da tatuagem correlacionada à profissão, apontando as áreas mais formais - ramos jurídicos, da saúde e administrativos - como aquelas em que essa estigmatização está mais presente. Elas também relacionaram a não estigmatização com profissões como designers, publicitários e profissionais de marketing e afirmaram que isso tende a mudar com o tempo. Mas, em algumas áreas, pode demorar muito, como citado pela advogada da existência de um movimento para a retirada do uso de ternos em dias quentes, mas nem a gravata conseguem flexibilizar, dizendo que até chegarem em uma não estigmatização da tatuagem, ainda há um longo percurso.

\section{Conclusão}

Apesar do grande aumento de adeptos à tatuagem no Brasil e um pouco mais de um terço da população ser tatuada, percebe-se que a tatuagem está passando a ser menos estigmatizada, ocorrendo uma ressignificação desta, de forma gradual, e não muito rápida. Em áreas profissionais cuja criatividade é inerente ao trabalho, a aceitação é maior, às vezes, até considerando a modificação positiva por associação à criatividade e à facilidade de expressão.

Porém, em campos mais formais, profissões mais antigas como a área jurídica, da saúde e administrativa, a resistência ainda é muito grande, a ponto de ser um critério para a desclassificação do 
candidato, dependendo do tamanho, desenho e local da tatuagem. 0 preconceito aos profissionais nessas áreas está presente, principalmente, quando o candidato fará atendimento ao público. Assim, recomenda-se aos profissionais de Administração de Recursos Humanos que tenham cuidado ao contratar candidatos que farão atendimento ao público em áreas de atuação conservadoras, para evitarem algum tipo de reação negativa do público atendido e consequente insatisfação com o atendimento. Esse seria um ponto negativo de se ter tatuagem. Essa recomendação é válida para o momento presente, enquanto um grupo da sociedade, demonstrando associar tatuagens chamativas com comportamentos violentos ou desvios de conduta, mas imagina-se que, daqui a alguns anos, essa realidade mude, pelo volume de pessoas tatuadas no Brasil, que além de ser grande, continua crescendo. Recomenda-se que esse dado seja reavaliado em futuras pesquisas no intuito de verificar se essa realidade foi alterada.

A tatuagem ainda é fortemente associada à desvio de conduta, falta de confiança e comportamentos violentos pela parcela conservadora da sociedade, portanto, para profissões com atendimento e/ou contato direto com o público, as pessoas tatuadas são, em sua maioria, não contratadas. Porém, para profissionais de recrutamento e seleção, os achados indicam que tatuagens de temas polêmicos representam mais registros de superação de quem as consome do que de rebeldia. A característica de superação é um ponto positivo dos tatuados, indicando pessoas, em certa medida, são mais resilientes e maduras emocionalmente, o que pode servir como referência para ocupação de vagas que demandem essa característica do funcionário. Todos os entrevistados, tanto os profissionais em formação quanto os profissionais de recrutamento e seleção, afirmaram acreditarem que a tendência é diminuir a visão negativa perante esta modificação cultural, porém, cada um apresentou a mudança com velocidades diferentes, sendo maior para áreas menos formais e menor para áreas formais e com contato direto ao público.

0 presente artigo apresenta como limitação as entrevistas com as profissionais em recrutamento e seleção terem sido realizadas pela plataforma on-line de comunicação Skype, devido à necessidade de distanciamento social pela pandemia Covid-19. Entende-se como limitação, por ser um estudo qualitativo aprofundado e, possivelmente, as entrevistas pelo Skype com as recrutadoras podem ter limitado nuances que, pessoalmente, seriam mais fáceis de observar e questionar. Todas as entrevistas com os 25 profissionais em formação foram realizadas antes da pandemia.

Como estudos futuros, sugere-se ampliar a pesquisa para profissionais em formação de cursos que não foram abordados neste estudo e replicar a pesquisa para observar se existe diferença de percepção das pessoas quanto ao consumo de tatuagens e colocação no mercado de trabalho em cidades de maior porte, em capitais ou em outras cidades do interior. Também se sugere a realização de pesquisa quantitativa para analisar possíveis diferenças no significado da tatuagem entre e para os profissionais em formação tatuados e a percepção dos recrutadores sobre esses diferentes profissionais em virtude da idade, gênero e classe social.

\section{Referências}

Atran, S., Medin, D.L. \& Ross, N. O. (2005). The cultural mind: Environmental decision making and cultural modeling within and across populations. Psychological Review, Los Angeles, Vol. 112(4), pp. 744-776.

Barbosa, F. L. S., Brito, A. dos S. \& Bizarria, F. P. de A. (2016). Tatuagens, Piercings e Diversidade Cultural: o que gestores dizem sobre esse tema? TPA - Teoria e Prática em Administração. Vol. 6(2), pp. 78-106. DOI: https://doi.org/10.21714/2238-104X2016v6i2-28192.

Bayer Jovens (2019). Tatuagens que melhoram a vida: As tattoos têm uma longa história e, para algumas pessoas, podem ser o caminho para a recuperação da autoestima e da alegria. Recuperado em: https://www.bayerjovens.com.br/pt/materia/?materia=tatuagens-que-melhoram-a-vida. Acessado em 12 de março de 2020.

Bell, S. (1999). Tattooed: A participant observer's exploration of meaning, Journal of American Culture, Vol. 22(2), pp. 53-58.

Buss, L. \& Hodges, K. (2017). Marked: Tattoo as an expression of psyche. Psychological Perspectives, Vol. 60(1), pp. 4-38.

Caregnato, R. C. A., \& Mutti, R. (2006). Pesquisa qualitativa: análise de discurso versus análise de conteúdo. Texto \& Contexto-Enfermagem, 15(4), pp. 679-684.

Caroni, M. M. \& Grossman, E. (2012). As marcas corporais segundo a percepção de profissionais de saúde: adorno ou estigma? Ciência \& Saúde Coletiva, Vol. 17(4), pp. 10611070. https://doi.org/10.1590/S1413-81232012000400027 
Carvalho, M. L. \& Grisci, C. L. I. (2003). Gerenciamento de impressão e produção de subjetividade em entrevista de seleção. RAE-eletrônica, Vol. 2(2), pp. 1-23.

Creswell, J. (1998). Qualitative inquiry and research design: Choosing among five traditions. Thousand Oaks, CA: Sage.

Exame (2011). 5 pesquisas que provam que a aparência importa (sim) para a carreira. Recuperado em: https://exame.com/carreira/5-pesquisas-que-provam-que-aparencia-importa-sim-para-a-carreira/. Acessado em 10 de março de 2020.

Kalanj-Mizzi, S. A., Snell, T. L. \& Simmonds, J. G. (2018). Motivations for multiple tattoo acquisition: an interpretative phenomenological analysis, Advances in Mental Health, DOI: 10.1080/18387357.2018.1537127.

Larsen, G., Patterson, M. \& Markham, L. (2014). 'A deviant art : tattoo-related stigma in an era of commodification.', Psychology and marketing., Vol. 31(8), pp. 670-681.

Le Breton, D. (2000). Anthropologie du Corps et Modernité, Paris, Quadrige/PUF.

Le Breton, D. (2004). Sinais de identidade: Tatuagens, piercings e outras marcas corporais. Lisboa: Miosótis. Edição e Distribuidora.

Minayo, M. C. S. (2009). Pesquisa Social: Teoria, método e criatividade. (Org.). Petrópolis: Editora Vozes.

Minayo, M. C. S. (2017). Amostragem e saturação em pesquisa qualitativa: Consensos e controvérsias, Revista de Pesquisa Qualitativa, Vol. 5(7).

Minayo, M. C. S. Deslandes, S. F. Cruz Neto, O.\& Gomes, R. (2002). Pesquisa Social: teoria métodos e criatividade. Petrópolis: Vozes.

Morais, B. V., Morais, T. H. \& Rugai, T. D. A. S. (2019). A percepção dos candidatos sobre a influência do estereótipo no processo de recrutamento e seleção. Revista Fatec Sebrae em Debate, Vol. 6(10).

Morse, J. M. (1994). Designing funded qualitative research. In: Norman, K. D.; Yvonna, S. L. (Eds.). Handbook of qualitative research. 2. ed. Thousand Oaks, CA: Sage,. pp. 220-2335.

Negri, A. D. (2011). Sobre liberdade e questões pertinentes ao preconceito automático nas sociedades descentradas, Revista Brasileira de Direito Constitucional, Vol. 17.

Patterson, M. (2018). Tattoo: marketplace icon, Consumption Markets \& Culture, Vol. 21(6), pp. 582589, DOI: $10.1080 / 10253866.2017 .1334280$.

Pedro, F. O. \& Aguiar, H. S. (2016). Visual Corporativo: A influência da tatuagem na carreira profissional. In: XXVII Enangrad, Campinas-SP.

Roberts, D. (2012). Secret Ink: Tattoo's place in contemporary American culture. The Journal of American Culture. Retrieved from https://onlinelibrary.wiley.com/doi/abs/10.1111/j.1542734X.2012.00804.X

Rosário, T. C. M. (2018). Discriminação no processo de recrutamento e seleção: tatuagens. Mestrado em Gestão de Recursos Humanos. Universidade Europeia Laureate International Universities.

Rossi, S. M. (2011). La Piel como Superfície Simbólica: procesos de Transculturación en el Arte Contemporáneo. Madrid: FCE.

Sebrae (2018). Mercado das tatuagens cresce $25 \%$ ao ano no Brasil, segundo Sebrae. Recuperado em: http://jornalismo.iesb.br/2020/04/28/mercado-das-tatuagens-cresce-25-ao-ano-brasil-segundosebrae/. Acessado em 10 de março de 2020.

Sellitz, C; Jahoda, M; Deutschi, M \& Cook, S. W. (1975). Métodos de pesquisa nas relações sociais. São Paulo: EPU.

Silva, A. N. \& Saraiva, L. A. S. (2014). Contornando o Estigma: uma análise dos estúdios de tatuagens de Belo Horizonte, Teoria e Prática em Administração, Vol. 4(1).

Stuppy, D. J., Armstrong, M. L. \& Casals-Ariet, C. (1998). Attitudes of health care providers and students towards tattooed people. Journal Advanced Nursing, Vol. 27(6), pp. 1165-1170.

Triviños, A. N. S. (1987). Introdução à pesquisa em ciências sociais: a pesquisa qualitativa em educação. São Paulo: Atlas, p. 91-114.

Vergara, S. C. (2007). Projetos e relatórios de pesquisa em administração. 8. ed. São Paulo: Atlas.

Zappellini, M. B.; Feuerschutte, S. G. (2015). 0 uso da triangulação na pesquisa científica brasileira em Administração. Administração: Ensino e Pesquisa, 16(2), 241-273.

Zestcott, C. A., Tompkins, T. L., Williams, M. K., Livesay, K. \& Chan, K. L. (2018). What do you think about ink? An examination of implicit and explicit attitudes toward tattooed individuals, The Journal of Social Psychology, Vol. 158(1), pp. 7-22, DOI: 10.1080/00224545.2017.1297286 
Anexo 1: Perfil dos profissionais em formação entrevistados

\begin{tabular}{|c|c|c|c|c|c|c|c|}
\hline $\begin{array}{l}\text { Entrevis- } \\
\text { tado }\end{array}$ & $\begin{array}{c}\text { Gê- } \\
\text { nero }\end{array}$ & Idade & $\begin{array}{l}\text { Idade } 1 \mathrm{o} \\
\text { Tatuagem }\end{array}$ & Curso & $\begin{array}{l}\text { Ano de } \\
\text { curso }\end{array}$ & $\begin{array}{l}\text { Quantidade } \\
\text { de tatuagens }\end{array}$ & Desenhos \\
\hline 1 & M & 22 & 18 & Física & $4^{\circ}$ & 3 & Data nascimento em $\mathrm{n}^{\circ}$ romanos; Ouro Bouros; Triângulo positivo \\
\hline 2 & $\mathrm{~F}$ & 25 & 15 & Matemática & $4^{\circ}$ & 4 & Borboleta; símbolo do infinito; personagem da Sininho; Santa Maria; Equação Matemática \\
\hline 3 & $\mathrm{~F}$ & 24 & 17 & $\begin{array}{l}\text { Matemática/ } \\
\text { Pedagogia }\end{array}$ & $4^{\circ} / 2^{\circ}$ & 8 & $\begin{array}{c}\text { (1) Equação; (2) Fita de cinema; (3) Espada ;(4 e 5) Skylines Umuarama e SP; (6) símbolo } \\
\text { feminino; (7) Flor; (8) Grl Power; }\end{array}$ \\
\hline 4 & $\mathrm{~F}$ & 21 & 18 & Química & $4^{\circ}$ & 4 & $\begin{array}{c}\text { Caveira; triângulo equilátero com flores; desenho de } 3 \text { mulheres; uma menina oferecendo o } \\
\text { Globo Mundial nas mãos }\end{array}$ \\
\hline 5 & $\mathrm{~F}$ & 22 & 18 & Química & $4 \underline{0}$ & 3 & Rosa dos ventos; estrutura química da dopamina; frase: "nunca foi sorte sempre foi Deus" \\
\hline 6 & M & 35 & 28 & Química & 5 은 & 1 & Uma mulher "mexicana" com a metade do rosto como caveira \\
\hline 7 & $\mathrm{~F}$ & 19 & 16 & Artes Cênicas & 4 & 17 & Mulheres negras; desenhos diversos; frases \\
\hline 8 & $\mathrm{~F}$ & 18 & 18 & Comunicação & $1 \stackrel{0}{1}$ & 1 & Coração \\
\hline 9 & M & 22 & 18 & Comunicação & 30 & 8 & Escrita ao inverso para ver em frente ao espelho; signo \\
\hline 10 & M & 19 & 18 & Comunicação & $2^{-}$ & 3 & Coração, cérebro, mãos \\
\hline 11 & M & 19 & 16 & Comunicação & 10 & 6 & Anjos e tribais \\
\hline 12 & $\mathrm{~F}$ & 22 & 18 & Comunicação & $2^{\circ}$ & 7 & Desenhos exclusivos feitos para ela \\
\hline 13 & M & 25 & 15 & Geografia & 5 & 30 & Desenhos diversos, bode \\
\hline 14 & $\mathrm{~F}$ & 22 & 17 & Geografia & 2 & 11 & Animais; animes; frases; diversos \\
\hline 15 & $\mathrm{~F}$ & 18 & 18 & Geografia & 1 & 1 & Símbolo de Banda \\
\hline 16 & $\mathrm{~F}$ & 22 & 17 & História & 5 & 6 & $\begin{array}{l}\text { Mulher no braço segurando bebê e arma; frase de homenagem para mãe; folha de maconha; } \\
\text { frase em homenagem a um escritor; frase de música }\end{array}$ \\
\hline 17 & $\mathrm{~F}$ & 24 & 17 & $\begin{array}{l}\text { Educação Fí- } \\
\text { sica }\end{array}$ & $4^{\circ}$ & 8 & $\begin{array}{c}\text { Mantra; Olho; Frase "A paz de estar em paz com Deus"; Desenho do Cazuza; YinYang; Me- } \\
\text { tade de um Gato; Constelação Signo Touro; Concha }\end{array}$ \\
\hline 18 & M & 23 & 21 & $\begin{array}{l}\text { Educação Fí- } \\
\text { sica }\end{array}$ & $3^{\circ}$ & 5 & $\begin{array}{c}\text { Par de luvas de luta; desenho Rick e Morty ; coração; jogo da velha; caveira do álbum do } \\
\text { Charlie Brown Jr }\end{array}$ \\
\hline 19 & $\mathrm{~F}$ & 23 & 14 & $\begin{array}{l}\text { Educação Fí- } \\
\text { sica }\end{array}$ & $4^{\circ}$ & 6 & $\begin{array}{l}\text { Palavra love mesclada com o símbolo do infinito; lua; mão (hamsá); Flor; Escrito japonês; } \\
\text { escrito em indiano }\end{array}$ \\
\hline 20 & $\mathrm{~F}$ & 21 & 14 & Enfermagem & $3^{\mathrm{o}}$ & 4 & Fé; ramo de flor; frase:" Be Brave"; desenho de uma rosa \\
\hline 21 & $\mathrm{~F}$ & 21 & 19 & Enfermagem & 3 & 1 & Rosa \\
\hline 22 & $\mathrm{~F}$ & 20 & 17 & Biomedicina & $6^{0}$ & 2 & $\begin{array}{c}\text { Saturno, triângulo uma flor, rosa dos ventos, libélula, símbolo do feminismo, contorno de } \\
\text { um corpo feminino }\end{array}$ \\
\hline 23 & $\mathrm{~F}$ & 22 & 20 & Biomedicina & $4 \underline{0}$ & 3 & Tubarão, frase "choose life", fractal \\
\hline 24 & $\mathrm{~F}$ & 20 & 18 & Biomedicina & $44^{\circ}$ & 2 & $\begin{array}{l}\text { Símbolo do feminismo em forma de coração com flores, escrito em inglês "Non-stop the in- } \\
\text { novation" com o desenho de um microscópio, um dna e uma celular em divisão }\end{array}$ \\
\hline 25 & $\mathrm{~F}$ & 33 & 32 & Farmácia & $5^{\circ}$ & 1 & Flor \\
\hline
\end{tabular}

(F: Feminino; M: Masculino; Comunicação: Comunicação e Multimeios). 